\title{
Epidemiology of Canine Parvovirus Enteritis among Hospitalized Dogs in Effurun/Warri Metropolitan Region of Delta State, Nigeria
}

\author{
Felix K. Shima1, Thaddaeus T. Apaa², Janet I. T. Mosugu' \\ ${ }^{1}$ Department of Veterinary Public Health and Preventive Medicine, University of Ibadan, Ibadan, Nigeria \\ ${ }^{2}$ Department of Veterinary Medicine, University of Agriculture, Makurdi, Nigeria \\ Email: kshimaelyx@gmail.com
}

Received 5 November 2014; revised 18 December 2014; accepted 6 January 2015

Copyright (C) 2015 by authors and OALib.

This work is licensed under the Creative Commons Attribution International License (CC BY). http://creativecommons.org/licenses/by/4.0/

\section{(c) (i) Open Access}

\begin{abstract}
Canine parvovirus enteritis has remained a problem in dog population worldwide. In Nigeria, dog owners and researchers have grossly neglected the disease even though it has been a frequent cause of morbidity and mortality of dogs. This retrospective study provides current information on the status of canine parvovirus enteritis by collating and analyzing data from clinical records of hospitalized dogs from 2000 to 2013 in Effurun/Warri metropolitan region. In the study, the endemicity of this disease with an overall prevalence of $13.4 \%$ for the past 14 years has been demonstrated. The infection rates were significantly associated with age, sex, breed and vaccination status $(P<\mathbf{0 . 0 0 0 1})$. Puppies from 0 to 5 months of age, male, breeds such as Alsatians, Mongrels, Rottweiler, indigenous dogs and unvaccinated dogs are at a higher risk. Furthermore, a seasonal pattern for the disease has been demonstrated with peak incidence recorded every 4 - 5 years with highest numbers of cases occurring in January (dry season) and July (wet season) of every year. Additionally, the study shows that a recovery rate of $84.3 \%$ was achieved following "aggressive" therapeutic management. There is therefore a need to enlighten veterinarians and dog owners on the status and importance of vaccination against this disease.
\end{abstract}

\section{Keywords}

Dogs, Canine Parvovirus Enteritis, Parvovirus, Prevalence, Risk Factors, Vaccination

Subject Areas: Veterinary Medicine

\section{Introduction}

The importance of dogs to man cannot be overstated. They are the most popular animal pets that even share the

How to cite this paper: Shima, F.K., Apaa, T.T. and Mosugu, J.I.T. (2015) Epidemiology of Canine Parvovirus Enteritis among Hospitalized Dogs in Effurun/Warri Metropolitan Region of Delta State, Nigeria. Open Access Library Journal, 2: e1208.

http://dx.doi.org/10.4236/oalib.1101208 
same environment with humans and have been trained to perform several functions. Dog population in Nigeria at present is unknown but was estimated to be 4.5 million for the past two decades [1].

Canine parvovirus enteritis (CPE) has become an important problem to dog population worldwide. The aetiology of CPE was first recognized three and half decades ago. Canine parvovirus enteritis is an acute, fatal and contagious gastrointestinal infection mostly seen in puppies from 6 to 20 weeks old [2]-[4]. Dogs of all ages, sexes and breeds can be affected. Experiences have shown that morbidity and mortality rates of CPE vary and are dependent on the immune status, age and how early treatment intervention is initiated.

Apart from dogs, parvovirus infection with CPV-2 strain has been reported in wild carnivores [5] [6]. The strains of the virus presently reported in dog population worldwide are CPV-2a, CPV-2b and CPV-2c [7]-[9]. In Nigeria, CPV-2a is the predominant strain in circulation presently [10] that causes haemorrhagic enteritis with serious morbidity and mortality in puppies. The virus has constituted a major challenge to dogs' survival rates in Nigeria despite the availability of safe and effective vaccines. One of the reviewed reports showed that over $95 \%$ of dogs' diarrheic faecal samples examined from Nigeria and South Africa were positive for parvovirus [10].

Dogs can get infected with this virus through direct or indirect transmissions. Direct transmission can be via contact with contaminated faeces and indirectly by contact with contaminated fomites such as clothing, feeding plates and vehicles etc. Indirect transmission can also be by contaminated environment as well as through insect and rodent vectors [9].

Clinically, the disease manifests either as cardiac or enteric form. The enteric form is very severe in puppies with no or inadequate maternal antibodies and those without or inadequate vaccination. The enteric form manifests as an acute onset of lethargy, anorexia, fever, vomiting and diarrhoea, which may contain mucus or blood and foul smell. The cardiac form is only seen in neonates infected in utero with respiratory or cardiovascular failure manifestations. The cardiac form is uncommon these days because effective immunizations of bitches protect puppies during their early period of life [4] [11].

Susceptibility to CPE by breed, age and sex [9] [12] and seasonal distribution [13] [14] as well has been described from some parts of the world. Work has also been done on CPE in Nigeria [10] [14]-[17]; however, there is limited data on the disease from many parts of the country despite the economic importance of the disease in dogs.

In Effurun/Warri metropolitan region, there have been several cases of morbidity and mortality in dogs due to CPE but there seems to be no published data available on the status as regards to prevalence, morbidity and mortality rates of the disease despite high dog population in the region. This is what the present study seeks to address.

\section{Material and Methods}

\subsection{Study Location}

Effurun/Warri metropolis is located in Delta State (Longitude $5^{\circ} 00^{\prime}$ and $6^{\circ} 45^{\prime} \mathrm{E}$; Latitude $5^{\circ} 00^{\prime}$ and $6^{\circ} 30^{\prime} \mathrm{N}$ ). The city is the major economic hub and the most populated area in Delta State. The Effurun/Warri metropolitan area of Delta State comprised of extended development from local government areas which are Warri, Uvwie, Udu, Ughelli, Sapele and Okpe. The region has a considerable number of dog population and growth. The common dog breeds seen in the area are exotic, indigenous breeds and mongrels with many of them kept mostly for companionship as pets, security or sentinel by companies and individuals, and for livelihood or commercial gains by dog breeders.

\subsection{Data Collection Procedure}

Retrospective study was conducted on diagnosed cases of CPE from clinical records of dogs presented at a private veterinary hospital in Effurun/Warri metropolis from 2000 to 2013. Data were abstracted by carefully reviewing the case records. Selection of cases was based on history, clinical signs and postmortem findings features of CPV enteritis recorded. Dogs with clear history of foul smelling diarrhoea, haemorrhagic diarrhoea or a tentative diagnosis of CPV infection were selected. The vaccination history, treatment outcome, age, sex, breeds of dog, month and year the dog was diagnosed/admitted were the study variables recorded. The vaccination history was categorized into three namely: vaccinated, unvaccinated and unknown vaccination status. Similarly, the treatment outcomes of the cases following medical intervention were classified as either "recovered or dead". 


\subsection{Data Analysis}

Data collected were analyzed with SPSS version 20 using descriptive and non-parametric Chi-squared statistics. Test of association between CPV enteritis and the different study variables were measured by Chi-squared analysis at $95 \%$ confidence limit $(P<0.05)$.

\section{Results}

Over the last fourteen years (2000-2013), medical records of 1527 dogs presented with different health challenges at a private veterinary hospital in Effurun-Warri region of Delta State revealed 204 (13.4\%) dogs were diagnosed positive for CPV enteritis. Table 1 depicts the distribution of diagnosed CPE cases by age, sex, vaccination status and medical treatment outcome. Figures 1-3 show the distribution of the diagnosed CPE cases by

Table 1. Distribution canine parvovirus enteritis cases by age, sex, vaccination status and treatment outcome.

\begin{tabular}{|c|c|c|c|c|c|c|c|c|}
\hline \multirow{2}{*}{\multicolumn{2}{|c|}{ Variables }} & \multicolumn{2}{|c|}{ CPV enteritis } & \multicolumn{2}{|c|}{$95 \% \mathrm{CI}$} & \multirow{2}{*}{$\mathbf{X}^{2}$} & \multirow{2}{*}{$d f$} & \multirow{2}{*}{ P-value } \\
\hline & & Freq. (n) & Percent (\%) & Lower & Upper & & & \\
\hline \multirow{3}{*}{ Sex } & Female & 86 & 42.2 & 35.3 & 49.5 & \multirow{3}{*}{5.020} & \multirow{3}{*}{1} & \multirow{3}{*}{0.025} \\
\hline & & & & & & & & \\
\hline & Male & 118 & 57.8 & 50.5 & 64.7 & & & \\
\hline \multirow{4}{*}{ Age } & 0 - 5 Mo & 123 & 60.3 & 53.4 & 67.2 & \multirow{4}{*}{72.912} & \multirow{4}{*}{2} & \multirow{4}{*}{$<0.0001$} \\
\hline & $6-11$ Mo & 55 & 27.0 & 21.1 & 32.8 & & & \\
\hline & Above 11 Mo & 26 & 12.7 & 8.3 & 17.6 & & & \\
\hline & Unvaccinated & 108 & 52.9 & 45.6 & 59.8 & & & \\
\hline \multirow[t]{2}{*}{ Vaccination status } & Vaccinated & 57 & 27.9 & 22.1 & 34.3 & \multirow[t]{2}{*}{37.676} & \multirow[t]{2}{*}{2} & \multirow[t]{2}{*}{$<0.0001$} \\
\hline & Unknown & 39 & 19.1 & 14.2 & 25.0 & & & \\
\hline \multirow{3}{*}{ Treatment outcome } & Dead & 32 & 15.7 & 10.8 & 21.1 & \multirow{3}{*}{96.078} & \multirow{3}{*}{1} & \multirow{3}{*}{$<0.0001$} \\
\hline & & & & & & & & \\
\hline & Recovered & 172 & 84.3 & 78.9 & 89.2 & & & \\
\hline Overall & & 204 & 100.0 & 100.0 & 100.0 & & & \\
\hline
\end{tabular}

$\mathrm{CI}=$ Confidence interval; $\mathrm{X}^{2}=$ Chi-squared value; $\mathrm{df}=$ Degree of freedom; Mo = Month.

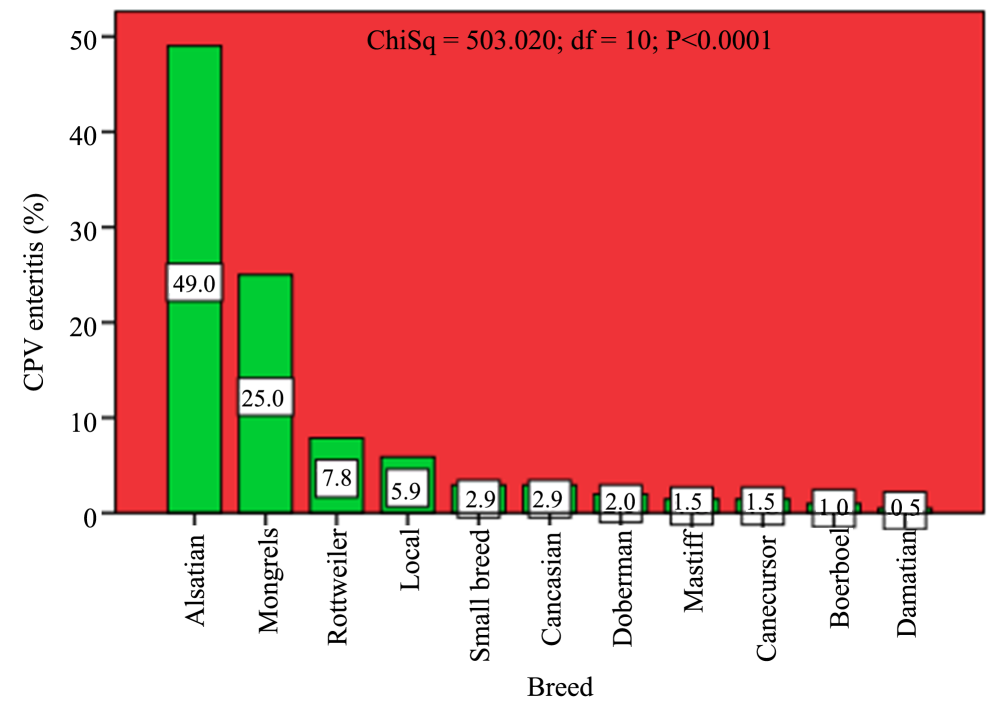

Figure 1. Distribution of the diagnosed canine parvovirus enteritis cases by breed of dog. 


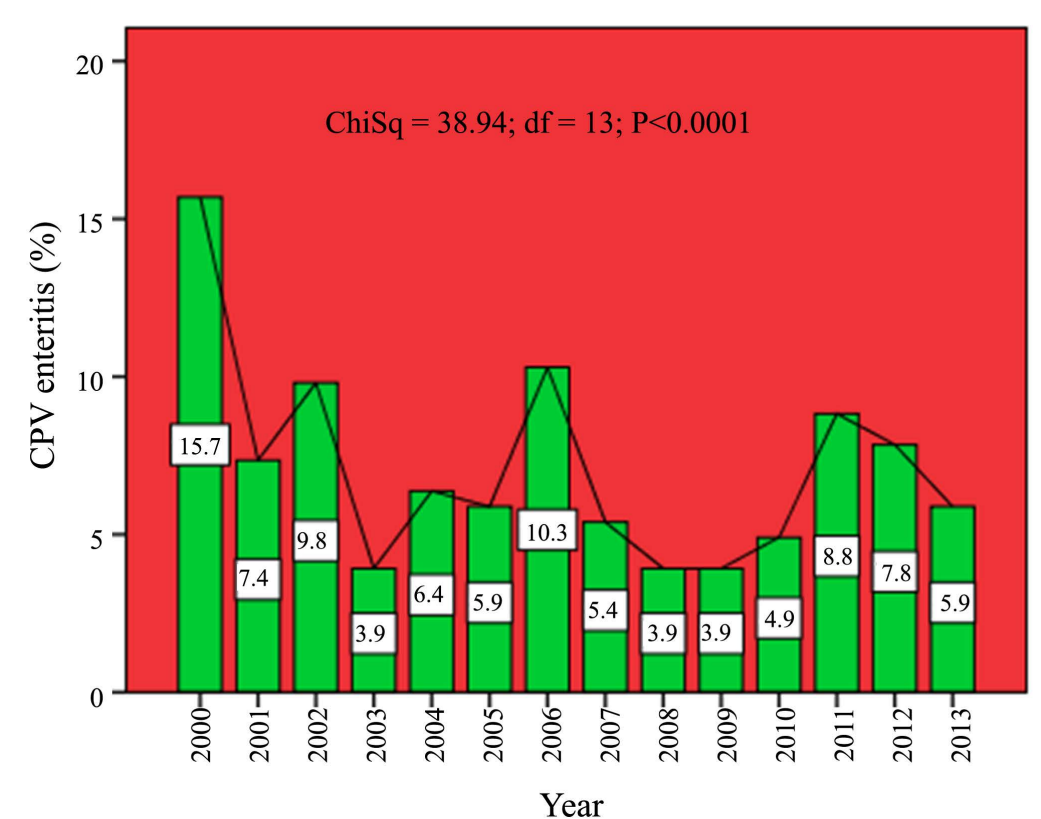

Figure 2. Profile showing the distribution of canine parvovirus enteritis cases by year.

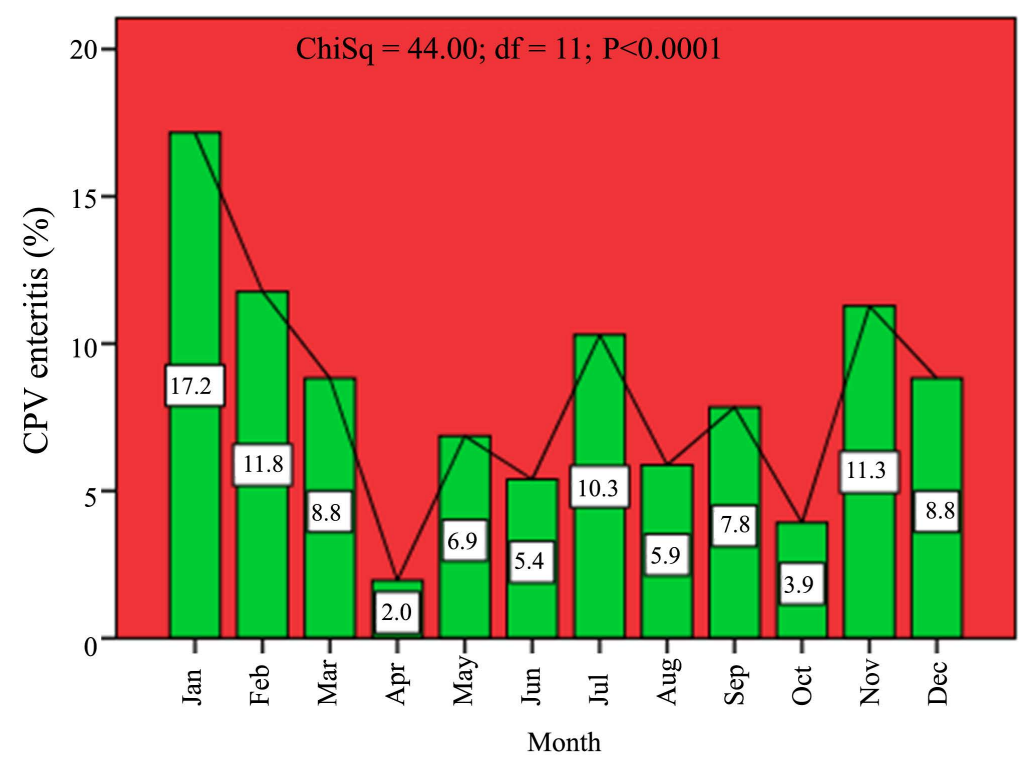

Figure 3. Profile showing the distribution of canine parvovirus enteritis cases by month.

dog breeds and dates the dogs were admitted or diagnosed positive for CPE (i.e. temporal or seasonal distribution of the CPE cases). Of the eleven dog breeds recorded in the study, the highest frequency of cases were obtained in Alsatian 100 (49.0\%), Mongrels 51 (25.0\%), Rottweiler 16 (7.8\%) and local breed 12 (5.9\%). Other dog breeds had the least numbers of cases. Breed was significant $\left(\mathrm{X}^{2}=503.02 ; P<0.0001\right)$ for CPV enteritis as shown in Figure 1. Furthermore, considering the dates the dogs were admitted or diagnosed positive for CPE, appreciable numbers of cases occurred in year 2000 (32; 15.7\%), 2002 (20; 9.8\%), 2006 (21; 10.3\%) and 2011 (18; 8.8\%), respectively (Figure 2). The peak incidence of cases occurred around January (35; 17.2\%) in the dry season months (i.e. November-April) and July $(21 ; 10.3 \%)$ in the wet season months (i.e. May-October) of every year as can be seen in Figure 3. 


\section{Discussions}

This study revealed that CPE has been endemic in the study location over the last fourteen years, with an overall incidence rate estimated at 13.4\% (204/1527). All ages, sexes and dog breeds under investigation were found to be statistically significantly $(P<0.0001)$ susceptible to the disease. The result of the study is comparable with the findings of other earlier works in Africa and other parts of the world [18]-[20]. In Africa, there is limited published data on CPV infection. Nonetheless, some reports available to us indicate that the disease is relatively high in dogs screened across the continent. In Nigeria and South Africa for instance, 30/31 (96.77\%) and 106/108 (98.15\%) dogs, respectively tested positive to parvovirus [10] while in Zimbabwe serological survey indicated 191/225 (84.89\%) of dogs screened had antibodies to CPV [21]. Most of the studies in Africa cited in this work focused less on the possible risks factors of the disease. It is worth knowing that the low incidence rate of $13.4 \%$ reported here is purely based on clinical cases from hospitalization. The incidence in the general dog population may be greatly higher as found in earlier reports in Africa including Nigeria [10] [14] [21].

Furthermore, reasons for breed susceptibility still remain unclear; however, CPE was more significantly associated with Alsatian (49.0\%), Mongrels (25.0\%), Rottweiler (7.8\%) and local dog (indigenous) breeds (5.9\%) as compared with the other seven breeds in this study. This finding is comparable with the findings of similar earlier studies which reported that Doberman pinscher, Rottweiler and Alsatian (German shepherd) are at higher risk of developing CPE [18] [20]. One study Slovenian [20] revealed that mixed breeds experienced 23.8\% mortality due to CPE followed by German shepherd with $16.7 \%$, Rottweiler 10.5\%, Labrador Retrievers 7.1\%, and Poodles 5.9\% while low numbers of cases were diagnosed in 21 other breeds. Again, another similar finding from Rio de Janeiro indicates that German shepherd, Rottweiler and Doberman Pinschers are at higher risk of developing CPV infection [19]. None of these studies however, found statistically significant association between CPE and the different dog breeds. Our study on the other hand found statistically significant association $(P<0.0001)$. The larger population of Alsatians as compared with other breeds in the study area could be responsible for the significant association recorded in this study.

The distribution of CPE cases was significantly associated $(P<0.025)$ with sex of the dogs. Higher incidence was recorded in male dogs (57.8\%) compared with females (42.2\%). This finding is in agreement with reports from other parts of the world. A study carried out in Slovenia showed that $83.3 \%$ of dogs that died due to CPE were males, and $16.7 \%$ were females and this association was statistically significant [20]. However, another study conducted in Rio de Janeiro found no significant difference in both sexes [19]. Since a good number of $\mathrm{CPE}$ cases also occurred in dogs of mating age in this study, the higher number of cases recorded in male than in female dogs may not be unrelated to straying and mating behaviour of male dogs. For instance, male dogs can travel a long distance to mate or compete with other males over a bitch on heat. At the point of conglomeration, they may become infected by the virus via contact with an infected bitch through sniffing and licking of the anal region which may be contaminated with infected faeces. It has been documented that faeco-oral transmission of canine parvovirus has remained the most important route of transmission [22]-[24]. Alternatively, it could be attributed to the larger population of male dogs as compare to females which in turn may be due to preference of male over female dog in the study area. However, sex susceptibility to CPV has remained elusive.

According to age group, CPE was significantly associated $(P<0.0001)$ with age of dog. The highest numbers of cases were found in puppies ( 0 - 5 months old; 60.3\%) than in adolescents ( 6 - 11 months old; $27.0 \%$ ) while dogs 12 months and above had the least number of cases (12.7\%). This finding corroborates the findings of similar earlier studies. Correlation of age group with deaths due to CPE was statistically significant in Slovenian study where the highest mortality (67.6\%) was observed in dogs younger than six month, the lowest (6.8\%) in dogs older than one year, from six months to one year, 27.5\% of dogs died due to CPE [20]. In Brazilian studies, most of the faecal samples that tested positive to CPV were obtained from 2 - 4 months old puppies [19] [25]. This shows that puppies are at a higher risk of this disease, age is a factor.

Considering vaccination histories of the dogs, it was revealed that unvaccinated dogs were more prone to CPE (108; 52.9\%) followed by vaccinated ones $(39 ; 27.9 \%)$ while those with unknown vaccination history had the least number of cases $(39 ; 19.1 \%)$. There was a statistically significant association $(P<0.0001)$ between vaccination status and the occurrence of CPE. The higher numbers of CPE cases recorded in unvaccinated dogs most likely suggests that they lack protection from the virus, which in turn could be due to ignorance on the part of owner, high cost of vaccination, poor husbandry, and faulty biosecurity practices [26].This therefore, suggests that unvaccinated status could be a risk factor.

Canine parvovirus enteritis cases recoded in the vaccinated dogs may be attributed to vaccine failure, which in 
turn may be due to interference with maternal-derived-antibodies (MDA) - the common cause of vaccine failure in puppies [27]. Several other reports have attributed vaccine failure to delay in maturation of the immune system, poor vaccinal immunogenicity, genetic incapability to respond to certain vaccine antigens, immune-suppression, and ineffective vaccine lots [28] [29] and break in vaccine cold chain resulting from improper vaccines storage. The vaccination history of the dogs in this study indicated that most of them received only the first dose of CPV vaccine and did not complete the ideal three primary serial vaccinations usually given at 6 weeks early in life, 3 - 4 weeks apart [12]. Hence, the inadequate vaccination dosages could be another contributing factor to the high incidence of cases revealed in the vaccinated dogs as they were not adequately protected early in life.

As regards treatment of $\mathrm{CPE}$, managing the disease is usually a difficult task to achieve as it often requires rigorous effort from the clinician. The success rate depends on how early it is diagnosed, age of the dog and intensive care given. A good number of the parvovirus infected dogs in this study recovered (84.3\%) after receiving treatment while $15.7 \%$ died despite medical interventions. This suggests that critical or intensive care management could increase the survival rate. There was a significant association $(P<0.0001)$ between CPV infection and the treatment outcomes. This finding is in agreement with previous studies which reported that untreated cases of parvovirus infection have a mortality rate approaching $90 \%$; but with vigorous therapy, survival rate may approach $68 \%$ - 95\% [4] [30].

Again, this study has demonstrated that CPE likely has a seasonal pattern. It was observed over the last 14 years that CPE gets peaked every 4 to 5 years (i.e. 2000, 2006 and 2011) with the highest numbers of cases occurring in the dry seasons between November and April (with a peak in January) followed by a semi-peak incidence in the July months in the rainy seasons (May to October) of every year. In contrast to our findings, other similar studies have reported diverse seasonal trends for the occurrence of this disease from their respective regions. For instance, in the city of Jos, Nigeria, the disease has been reported to be most prevalent between May and June [13]. In Canada, it occurs more likely between the months of July and September [12]. The differences in the temporal or seasonal distribution of the disease between the present study and the other studies could be attributed to differences in climate of different geographical locations.

\section{Conclusion}

This study has given insights into the endemicity of CPE, its possible seasonal trend or temporal distribution and the likely predisposing factors in and around Effurun/Warri metropolitan region. This information may perhaps be valuable to veterinarians, dog owners and prospective dog owners in taking adequate control and preventive measures generally but particularly during the high prevalence period. Hence, it is recommended that vaccination of pets against canine parvovirus, which is cheaper than chemotherapeutic management, safe and effective, should be given utmost priority in order to reduce morbidity and mortality due to CPE.

\section{Acknowledgements}

We are grateful to the management of the private veterinary hospital in Effurun/Warri metropolis for allowing us free access to the dogs' clinic records used in this study; and to Dr. F.A. Gberindyer for reviewing this article.

\section{References}

[1] Bourn, D., Wint, W., Blench, R. and Woolley, E. (1994) Nigerian Livestock Resources Survey. World Animal Review, 78, 49-58.

[2] Appel, M.J.G., Cooper, B.J., Griesen, H. and Carmichael, L.E. (1978) Status Report: Canine Viral Enteritis. Journal of the American Veterinary Medical Association, 173, 1516-1518.

[3] Carmichael, L.E. (2005) An Annotated Historical Account of Canine Parvovirus. Journal of Medicine B: Infectious Diseases, Veterinary Public Health, 52, 303-311.

[4] The Merck Veterinary Manual (2006) Canine Parvovirus. http://www.merckvetmanual.com/mvm/index.jsp?cfile=htm/bc/23301.htm.

[5] Steinel, A., Munson. L., Vuuren, M. and Truyen, U. (2000) Genetic Characterization of Feline Parvovirus Sequences from Various Carnivores. Journal of Genomics and Virology, 81, 345-350.

[6] Touihri, L., Bouzid, I., Daoud, R., Desario, C., Founa el goulli, A., Decaro, N., Ghorbel, A., Buoanavoglia, C. and Bahloul, C. (2009) Molecular Characterization of Canine Parvovirus-2 Variants Circulating in Tunisia. Virus Genes, 38, 249-258. http://dx.doi.org/10.1007/s11262-008-0314-1 
[7] Shackelton, L.A., Parrish, C.R., Truyen, U. and Holmes, E.C. (2005) High Rate of Viral Evolution Associated with the Emergence of Carnivore Parvovirus. Proceedings of the National Academy of Sciences, USA, 102, 379-384. http://dx.doi.org/10.1073/pnas.0406765102

[8] Decaro, N., Martella, V., Desario, C., Bellacicco, A.L., Camero, M., Manna, L. and Buonavogolia, C. (2006) First Detection of Canine Parvovirus Type 2c in Pups with Haemorrhagic Enteritis in Spain. Journal of Medicine B: Infectious Diseases, Veterinary Public Health, 53, 468-472.

[9] Foster and Smith (2011) Parvovirus: Serious Diarrhea in Puppies \& Dogs. www.peteducation.com/article.cfm?c=2+2102\&aid $=467$

[10] Dogonyaro, B.B. (2010) Molecular Characterization of Canine Parvovirus Strains from Domestic Dogs in South Africa and Nigeria. M.Sc. Thesis, Department of Veterinary Tropical Disease, University of Pretoria, Pretoria, 1-106.

[11] Schatzberg, S.J., Haley, N.J.B.S., Bar, S.C., de Lahunta, A., Kornegay, J.N. and Sharp, N.J.H. (2003) Polymerase Chain Reaction (PCR) Amplification of Parvoviral DNA from the Brains of Dogs and Cats with Cerebellar Hypoplasia. Journal of Veterinary Internal Medicine, 17, 538-544.

[12] Nelson, R.W. and Couto, C.G. (1998) Small Animal Internal Medicine. 2nd Edition, Mosby, Maryland Heights.

[13] Houston, D.M., Ribble, C.S. and Head, L.L. (1996) Risk Factors Associated with Parvovirus Enteritis in Dogs: 283 Cases. Journal of the American Veterinary Medical Association, 208, 542-546.

[14] Mohammed, J.G., Ogbe, A.O., Zwandor, N.J. and Umoh, J.U. (2005) Risk Factors Associated with Canine Parvovirus Enteritis in Vom and Environs. Animal Research International, 2, 366-368.

[15] Kamalu, B.P. (1985) Canine Parvovirus in Nigeria. Journal of Small Animal Practice, 26, 663-668. http://dx.doi.org/10.1111/j.1748-5827.1985.tb02193.x

[16] Eghafona, N.O., Jacob, J. and Yah, S.C. (2007) Evaluation of Post-Vaccination Immunity to Canine Distemper and Parvoviruses in Benin City, Nigeria. African Journal of Biotechnology, 6, 1898-1904.

[17] Nwoha, R.I.O. (2011) Parvoviral Enteritis in a Dog: Case Report and Review of the Literature. Continental Journal of Veterinary Science, 5, 6-10.

[18] Glickman, L.T., Domanski, L.M., Patronnek, G.J. and Visintainer, F. (1985) Breed-Related Risk Factors for Canine Parvovirus Enteritis. Journal of the American Veterinary Medical Association, 187, 589-594.

[19] Castro, T.X., Miranda, S.C., Labarthe, N.V., Silva, L.E. and Cubel Garcia, R.C.N. (2007) Clinical and Epidemiological Aspects of Canine Parvovirus (CPV) Enteritis in the State of Rio de Janeiro: 1995-2004. Arquivo Brasileiro de Medicina Veterinariae Zootecnia, 59, 333-339. http://dx.doi.org/10.1590/S0102-09352007000200010

[20] Gombac, M., Svara, T., Tadic, M. and PogacNik, M. (2008) Retrospective Study of Canine Parvovirosis in Slovenia. Case Report. Slovenia Veterinary Research, 45, 73-78.

[21] Mcree, A., Wilkes, R.P., Dawson, J., Parry, R., Foggin, C., Adams, H., et al. (2014) Serological Detection of Infection with Canine Distemper Virus, Canine Parvovirus and Canine Adenovirus in Communal Dogs from Zimbabwe'. Journal of the South African Veterinary Association, 85, Art. \#1110, 2 p.

[22] Pollock, R.V. (1982) Experimental Canine Parvovirus Infection in Dogs. Cornell Veterinary Laboratory, 72, $103-119$.

[23] Carmichael, L.E. (1994) Canine Parvovirus Type-2. An Evolving Pathogen of Dogs. Veterinary Medicine, 135, $590-464$.

[24] Decaro, N., Desario, C., Campolo, M., Elia, G., Martella, V., Ricci, D., Lorusso, E. and Buonavogolia, C. (2005) Clinical and Virological Findings in Pigs Naturally Infected by Canine Parvovirus Type 2 Glu-426 Mutant. Journal of Veterinary Diagnostic Investigations, 17, 133-138. http://dx.doi.org/10.1177/104063870501700206

[25] Cubel Garcia, R.C.N., Pinto, A.M.V., Costa, A.P., Maciel, B.M., Oliveira, L.H.S., et al. (2014) Canine Parvovirus Infection in Puppies with Gastroenteritis in Niteroi, Rio de Janeiro, Brazil from 1995-1997. Brazilian Journal of Veterinary Research and Animal Sciences, 51, 1413-9596. http://dx.doi.org/10.1590/S1413-95962000000200008

[26] Muzaffar, K.A., Rabbni, M., Muhammad, K., Murtaza, N. and Nazir, J. (2006) Isolation and Characterization of Canine Parvovirus Froma Vietnamese Dog. Archives of Virology, 149, 2261-2269.

[27] Pollock, R.V.H. and Carmichael, L.E. (1982) Maternally Derived Immunity to Canine Parvovirus Infection: Transfer, Decline and Interference with Vaccination. Journal of the American Veterinary Medical Association, 180, 37-42.

[28] Tizzard, I. and Yawei, N. (1998) Use of Serologic Testing to Assess Immune Status of Companion Animals. Journal of the American Veterinary Medical Association, 213, 54-60.

[29] Schultz, R.D. (2000) Considerations in Designing Effective and Safe Vaccination Programs for Puppies. In: Carmichael, L.E., Ed., Recent Advances in Canine Infectious Diseases, International Veterinary Information Service, Ithaca Document Number A0110.0500. www.ivis.org/advances/infect Dis Carmichael/schultz/reference.asp

[30] Prittie, J. (2004) Canine Parvoviral Enteritis: A Review of Diagnosis, Management, and Prevention. Journal of Veterinary Emergency and Critical Care, 14, 167-176. http://dx.doi.org/10.1111/j.1534-6935.2004.04020.x 